\title{
PENGARUH MINAT DAN MOTIVASI BERWIRAUSAHA TERHADAP JIWA WIRAUSAHA SISWA
}

\author{
Fitri Nurlaili ${ }^{1),}$ Sinta Terisnawati ${ }^{2}$ \\ Universitas Banten Jaya \\ Serang, Indonesia

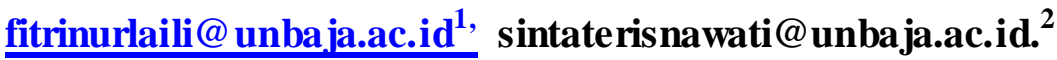

\begin{abstract}
This research aims to know whether the entrepreneurial interest and entrepreneurship motivation influence entrepreneurial spirit and how much interest and motivation of entrepreneurship influence on entrepreneurial spirit of students. This research conducted during Juni 2019 at SMK Negeri 7 Kota Serang. The population in this research were student of SMK Negeri 7 Kota Serang, sampling using simple random sampling. The data was obtained by distributing questionnaries to 109 respondents. Testing the hypothesis with multiple regression analysis, $t$-test, f-test, and coefficient of determination. The results of this study indicated that: (1) There was a positive and significant influence of interest in entrepreneurship on entrepreneurial spi rit, this was evidenced by having a regression coefficient $t_{\text {count }}>t_{\text {table }}$ of $(2.781>1,982)$ and a significant value of 5\%, (2) There was a positive and significant effect of entrepreneurial motivation on entrepreneurial spirit evidenced by having a regression coefficient $t_{\text {count }}>t_{\text {table }}$ of $(4,904>1,982)$ and a significant value of 5\%, (3) There was a positive and significant influence of interest and motivation in entrepreneurship together on entrepreneurial spirit. This was evidenced by having a regression coefficient $f_{\text {count }}>f_{\text {tabel }}$ of $(50,478>3.08)$ and a significant value of $5 \%$, (4) the coefficient of determination (adjusted R2) obtained at 0.478 or $47.8 \%$, while the rest is $52.2 \%$ Entrepreneurial spirit was influenced by variables other variables not examined in this study.
\end{abstract}

Keywords: Entrepreneurial Interest, EntrepreneurshipMotivation, EntrepreneurialSpirit.

\section{PENDAHULUAN}

Pengangguran di Indonesia berada pada kondisi yang sangat memprihatinkan, Badan Pusat Statistik Nasional menyatakan bahwa tingkat pengangguran terbuka per Agustus 2018 mencapai $5,34 \%$, pengangguran terbesar berasal dari Sekolah Menengah Kejuruan yaitu mencapai 11,24\%.( BPS. go.id), untuk Provinsi Banten pengangguran per Agustus 2018 menunjukkan bahwa tingkat pengangguran berada pada $8,52 \%$ dan menjadikan Banten sebagai provinsi dengan jumlah pengangguran tertinggi di Indonesia (radar banten.co.id), tingkat pengangguran terbuka lulusan SMK juga menempati posisi tertinggi dibanding jenjang pendidikan lain yaitu 14,23\% $\begin{array}{lll}\text { pada } & \text { Agustus } & 2018\end{array}$ (https://banten.bps.go.id/). Pengangguran terjadi karena perbandingan antara jumlah penawaran kesempatan kerja tidak sebanding dengan jumlah lulusan hal ini mengindikasikan para angkatan kerja lebih memilih mencari pekerjaan dibanding menjadi seorang wirausaha.

Proporsi wirausaha di Indonesia baru mencapai $3,1 \%$ dari jumlah masyarakat di usia produktif Indonesia, 
berbeda dengan jumlah wirausaha di Negara maju yang mencapai $14 \%$ (www.cnnindonesia.com), hal ini diperkuat dengan presiden JokoWidodo menyatakan minimnya peringkat kewirausahaan dari Global Enterpreneur Index tahun 2017 menunjukkan bahwa peringkat kewirausahaan Indonesia berada di rangking 90 dari 137 negara, di tingkat Asia Pasifik peringkat Indonesia berada di posisi ke 16 dari 24 negara (www.merdeka.com)

Wirausaha merupakan salah satu pilar ekonomi negara, lembaga pendidikan formal hendaknya mampu mendorong siswanya menjadi seorang wirausaha. SMK merupakan lembaga pendidikan formal yang tepat untuk menumbuhkan jiwa kewirausahaan pada siswa. Menurut penjelasan UndangUndang Sistem Pendidikan Nasional (UU Sisdiknas) Nomor 20 Tahun 2003 Pasal 15, SMK merupakan pendidikan menengah yang mempersiapkan peserta didiknya terutama untuk bekerja dalam bidang keahlian tertentu.

SMK Negeri 7 Kota Serang adalah salah satu sekolah formal yang memiliki kepedulian tinggi terhadap meningkatnya jumlah wirausaha dengan memberikan seluruh siswanya mata pelajaran kewirausahaan, namun berdasarkan dokumentasi diketahui bahwa proporsi wirausaha dari lulusan SMK Negeri 7 masih relatif rendah.

TABEL 1. DATA KETERSERAPAN LULUSAN

\begin{tabular}{|c|c|c|c|c|c|}
\hline \multirow[t]{2}{*}{ No } & \multirow{2}{*}{$\begin{array}{r}\text { Tahun } \\
\text { Pelajaran }\end{array}$} & \multirow{2}{*}{$\begin{array}{l}\text { Jumlah } \\
\text { Alumni }\end{array}$} & \multicolumn{2}{|c|}{ Keterserapan } & \multirow[t]{2}{*}{ Keterangan } \\
\hline & & & Orang & $\%$ & \\
\hline \multirow[t]{5}{*}{1} & $2015-2016$ & 113 & 68 & 60.18 & DU/DI \\
\hline & & & 22 & 19.47 & Kuliah \\
\hline & & & 10 & 8.85 & Enterpreneur \\
\hline & & & 13 & 11.5 & lain-lain \\
\hline & JUMLAH & & 113 & 100 & \\
\hline \multirow[t]{5}{*}{2} & 2016-2017 & 178 & 124 & 69.66 & DU/DI \\
\hline & & & 26 & 14.61 & Kuliah \\
\hline & & & 9 & 5.06 & Enterpreneur \\
\hline & & & 19 & 10.67 & lain-lain \\
\hline & JUMLAH & & 178 & 100 & \\
\hline \multirow[t]{3}{*}{3} & 2017-2018 & 272 & 147 & 54.04 & DU/DI \\
\hline & & & 43 & 15.81 & Kuliah \\
\hline & & & 52 & 19.12 & Enterpreneur \\
\hline
\end{tabular}




\begin{tabular}{cccc}
\hline & 30 & 11.03 & lain-lain \\
JUMLAH & 272 & 100 & \\
\hline
\end{tabular}

Sumber : Dokumentasi SMK N 7 Kota Serang

Minimnya jumlah lulusan menjadi wirausaha memperlihatkan bahwa jiwa wirausaha belum tertanam dengan baik. Jiwa wirausaha merupakan merupakan nyawa kehidupan dalam kewirausahaan yang pada dasarnya merupakan sikap dan perilaku kewirausahaan yang ditunjukkan melalui sifat, karakter dan watak seseorang yang memiliki kemauan dalam mewujudkan gagasan inovatif ke dalam dunia nyata secara kreatif. Nurbudiyani (2015: 12) jiwa wirausaha akan mengalami pertumbuhan seiring pertumbuhan kebutuhan seseorang jiwa wirausaha akan terlihat dari kemampuan untuk penuh rasa percaya diri, memiliki inisiatif, memiliki motif berprestasi, memiliki jiwa kepemimpinan dan berani mengambil resiko dengan penuh tantangan (Suryana, 2014:22). Jiwa wirausaha perlu ditumbuhkan dengan berbagai hal beberapa diantaranya adalah dengan menumbuhkan minat dan motivasi berwirausaha. Minat seseorang terhadap suatu obyek diawali dari perhatian seseorang terhadap obyek yang dituju. Minat merupakan suatu hal yang sangat menentukan dalam setiap usaha, minat perlu ditumbuh kembangkan dalam diri seorang wirausaha.
Minat berwirausaha merupakan keinginan, ketertarikan, serta kesediaan individu melalui ide-ide yang dimiliki untuk bekerja keras atau berkemauan keras untuk berusaha memenuhi kebutuhan hidupnya, tanpa merasa takut resiko yang akan terjadi, dapat menerima tantangan, percaya diri, kreatif, dan inovatif serta mempunyai kemampuan dan keterampilan untuk memenuhi kebutuhan. (Fu'adi, 2009: 93).

Setiap perbuatan yang dilakukan manusia pasti berasal dari dorongan baik dari dalam diri maupun dari luar pribadi yang bersangkutan, Proses yang mendorong atau mempengaruhi seseorang melakukan sesuatu dikenal dengan istilah motivasi. Motivasi seseorang untuk melakukan kegiatan wirausaha berasal dari keinginan untuk memperoleh laba, memiliki kebebasan baik dari aturan, budaya organisasi, minat berwirausaha juga dipengaruhi oleh impian personal dan rasa kemandirian (Saiman, 2015).

Motivasi berwirausaha menurut Zimmerer dalam Us waturrasul (2011: 358) motivasi berwirausaha adalah suatu sesuatu yang melatar belakangi atau mendorong seseorang melakukan aktivitas dan memberi energi yang mengarah pada 
pencapaian kebutuhan, memberi kepuasan ataupun mengurangi ketidak seimbangan dengan membuka suatu usaha atau bisnis.

Pentingnya peningkatan jiwa wirausaha dan kenyataan bahwa pengangguran masih menjadi masalah utama ekonomi dan rendahnya jumlah wirausaha maka diperlukan penelitian mengenai hal- hal yang mempengaruhi jiwa wirausaha. dalam penelitian ini hanya akan diteliti 2 variabel yaitu minat berwirausaha dan motivasi berwirausaha terhada jiwa wirausaha

\section{METODE PENELITIAN}

Penelitian ini akan dilakukan di SMK Negeri 7 Kota Serang yang beralamat di Jl. Raya Bangdes, Kampung Baru, Terminal Pakupatan, Cipocok Jaya, Panancangan, Kota Serang, Banten 42124. Penelitian dilaksanakan pada bulan Juni 2019. Penelitian ini menggunakan pendekatan kuantitatif bersifat deskriptif .

Populasi dari penelitian ini adalah seluruh siswa SMK Negeri 7 Kota serang yang berjumlah 1087 siswa, Arikunto (2016: 95) "Penelitian yang populasinya kurang dari 100, lebih baik diambil semua namun jika populasi lebih dari 100, sampel dapat diambil 10-15\% atau 20-25\%". Dalam penelitian ini digunakan sampel sebesar $10 \%$ dari jumlah populasi yaitu sebesar 109 siswa dengan teknik simple random sampling.

Teknik pengumpulan data yang digunakan dalam penelitian ini menggunakan kuesioner dan dokumentasi. Instrumen penelitian menggunakan lembar kuesioner tertutup sehingga responden tinggal memilih jawaban yang sudah disediakan. Untuk mengetahui tanggapan responden jenis kuesioner berbentuk rating scale dengan menggunakan skala likert.

Penelitian terdapat dua variabel bebas dan satu variabel terikat, sebagai variabel bebas adalah minat berwirausaha $\left(\mathrm{X}_{1}\right)$, motivasi berwirausaha $\left(\mathrm{X}_{2}\right)$, sedangkan variabel terikat adalah jiwa wirausaha (Y).

a. Minat Berwirausaha

Minat berwirausaha adalah suatu keinginan, ketertarikan, perhatian, dan bekerja keras untuk menciptakan suatu usaha yang kemudian mengorganisir, mengatur, menanggung resiko serta mengembangkan usaha yang diciptakannya. Variabel minat berwirausaha memiliki indikator yang mendukung timbulnya minat diantaranya: (1) keinginan, (2) ketertarikan, (3) keterlibatan (Fu'adi, 2009: 93) 
b. Motivasi Berwirausaha

Motivasi berwirausaha adalah dorongan atau daya penggerak yang mengarahkan seseorang melakukan suatu tindakan untuk memenuhi hal yang dibutuhkan atau diharapkan untuk suatu tujuan yang direncanakan. Motivasi berwirausaha juga dapat diartikan sebagai dorongan yang menyebabkan seseorang melakukan suatu kegiatan berwirausaha. Faktor yang mempengaruhi motivasi berwirausaha adalah: (1) laba, (2) kebebasan, (3) impian personal, (4) kemandirian (Saiman, 2015: 26).

c. Jiwa Wirausaha

Jiwa wirausaha adalah sifat pikiran, perasaan untuk menciptakan nilai tambah dari peluang bisnis, mengelola sumber daya melalui ide-ide inovatif ke dalam dunia nyata secara kreatif. Jiwa wirausaha ini muncul karena adanya pola pikir dan persepsi yang merespon adanya faktor yang mempengaruhi, diantaranya faktor yang berpengaruh pada jiwa wirausaha adalah: (1) percaya diri, (2) inisiatif, (3) motif berprestasi, (4) jiwa kepemimpinan, (5) berani mengambil resiko (Suryana, 2014: 22).

Teknik keabsahan data menggunakan validitas dan realibilitas. Uji prasyarat yang dilakukan dalam penelitian ini adalah uji normalitas, uji linearitas. Sedangkan uji hipotesis dilakukan menggunakan analisis regresi berganda, uji signifikansi parameter individual ( uji statistik $t$ ), uji signifikansi simultan ( Uji statatistik $F$ ), dan koefisien determinasi $\left(R^{2}\right)$

\section{HASIL PENELITIAN DAN} PEMBAHASAN

Penelitian dilakukan di SMK Negeri 7 Kota Serang dengan jumlah responden sebanyak 109 siswa, data dikumpulkan menggunakan kuesioner dengan 15 pertanyaan mengenai minat berwirausaha, 20 pertanyaan mengenai motivasi berwirausaha dan 15 pertanyaan mengenai jiwa wirausaha. kuesioner berbentuk rating scale dengan menggunakan skala likert dengan rentang penilaian 1-4. Kualitas kuesioner dapat diketahui dengan uji validitas dan realibilitas, pengujian terhadap kuesioner dilakukan kepada 30 responden. Kuesioner dinyatakan valid apabila $r$ hitung $>r$ tabel.,$r$ tabel pada penelitian ini adalah 0,361. Hasil validitas menunjukkan bahwa dari 15 pertanyaan mengenai minat berwirausaha 13 item dinyatakan valid, pada motivasi berwirausaha seluruh item valid dan pada jiwa wirausaha 14 item valid.

Selain validitas kualitas kuesioner diketahui dengan uji reliabilitas. Uji 
reliabilitas dilakukan dengan metode alpha cronbach. Kuesioner dikatakan reliabel apabila mempunyai alpha lebih dari 0.6.

Tabel 2. Hasil Uji Reliabilitas

\begin{tabular}{llc}
\hline No & Variabel & r Cronbach Alpha \\
\hline 1 & $\begin{array}{l}\text { Minat } \\
\text { berwirausaha }\end{array}$ & 0.885 \\
2 & $\begin{array}{l}\text { Motivasi } \\
\text { berwirausaha }\end{array}$ & 0.934 \\
3 & Jiwa & 0.919 \\
& Wirausaha & \\
\hline
\end{tabular}

Sumber: Data Primer yang diolah 2019

Berdasarkan hasil perhitungan diketahui bahwa seluruh variabel memiliki reliabilitas yang sangat kuat. Hal ini menunjukkan bahwa semua item dapat konsisten ketika digunakan untuk penelitian kembali
Setelah diketahui kualitas kuesioner maka dilakukan Uji prasyarat analisis, uji yang digunakan adalah uji normalitas dan uji linearitas. Uji normalitas digunakan untuk menguji apakah data yang diperoleh memiliki sebaran data yang normal, maksudnya penyebaran nilai dari sampel telah mencerminkan populasi. Kriteria yang digunakan yaitu data dikatakan distribusi normal jika Asymp. Sig (p) pada output Kolmogorov-Smirnov test > dari alpha yang di tentukan yaitu $5 \%(0.05)$.

Tabel 3 Uji Normalitas

\section{One-Sample Kolmogorov-Smirnov Test}

\begin{tabular}{|c|c|c|}
\hline & & $\begin{array}{l}\text { Unstandardized } \\
\text { Residual }\end{array}$ \\
\hline $\mathrm{N}$ & & 109 \\
\hline Normal Parameters ${ }^{\mathrm{a}, \mathrm{b}}$ & Mean &, 0000000 \\
\hline & Std. & 4,27606772 \\
\hline & Deviation & \\
\hline Most Extreme & Absolute & ,50 \\
\hline Differences & Positive &, 50 \\
\hline & Negative &,- 50 \\
\hline Test Statistic & &, 50 \\
\hline Asymp. Sig. (2-tailed) & &, $200^{\mathrm{c}, \mathrm{d}}$ \\
\hline
\end{tabular}

Sumber: Data Primer yang diolah 2019

Berdasarkan data di atas hasil Asymp. Sig sebesar 0.200 lebih besar dari 0.05. Maka dapat disimpulkan bahwa data berdistribusi normal.

Pengujian linearitas memiliki tujuan untuk mengetahui apakah data yang terkumpul sesuai dengan garis linear. Peningkatan atau penurunan kuantitas variabel akan diikuti oleh peningkatan atau penurunan kuantitas pada variabel lainnya. Dikatakan linear apabila $\mathrm{F}_{\text {hitung }}<$

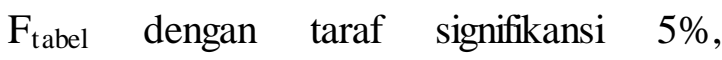


mengacu pada $\mathrm{dk}$ pembilang (k-1) dan $\mathrm{dk}$ penyebut (n- k).

\section{Tabel 4. Hasil Uji Linearitas}

\begin{tabular}{|c|c|c|c|}
\hline $\begin{array}{l}\text { Model } \\
\text { Hubungan }\end{array}$ & $\overline{\mathbf{F}_{\text {hitung }}}$ & $\overline{F_{\text {tabel }}}$ & Ket \\
\hline $\mathrm{X} 1$ dengan $\mathrm{Y}$ & 2,019 & 3,082 & Linear \\
\hline $\mathrm{X} 2$ dengan $\mathrm{Y}$ & 1,871 & 3,082 & Linear \\
\hline
\end{tabular}

Masing-masing hubungan antar variabel lebih kecil dari $F_{\text {tabel }}\left(F_{\text {hitung }}<\right.$
$\left.F_{\text {tabel }}\right)$. Dengan demikian semua model hubungan berstatus linear.

Uji hipotesis dilakukan dengan analisis regresi ganda yang bertujuan untuk mengetahui ada tidaknya pengaruh variabel bebas terhadap variabel terikat. Dari perhitungan yang telah dilakukan diperoleh persamaan regresi linear ganda sebagai berikut:

Tabel 5. Tabel Koefisien Regresi

\section{Coefficients $^{\mathrm{a}}$}

\begin{tabular}{|c|c|c|c|c|c|c|c|c|}
\hline \multirow[t]{3}{*}{ Model } & \multirow[t]{3}{*}{$\begin{array}{c}\text { Unstandardized } \\
\text { Coefficients }\end{array}$} & \multirow{2}{*}{\multicolumn{3}{|c|}{$\begin{array}{c}\text { Standardized } \\
\text { Coefficients } \\
\text { Std. }\end{array}$}} & \multirow[t]{3}{*}{$\mathrm{t}$} & \multirow[t]{3}{*}{ Sig. } & \multicolumn{2}{|c|}{$\begin{array}{l}\text { Collinearity } \\
\text { Statistic }\end{array}$} \\
\hline & & & & & & & Tolerance & VIF \\
\hline & & B & Error & Beta & & & & \\
\hline \multirow[t]{3}{*}{1} & ( Constant) & 12.934 & 3.462 & & 3.736 & 000 & & \\
\hline & $\begin{array}{l}\text { Minat } \\
\text { berwirausaha }\end{array}$ & .265 & .095 & .270 & 2.785 & 006 & .513 & 1.948 \\
\hline & $\begin{array}{l}\text { Motivasi } \\
\text { Berwirausaha }\end{array}$ & .344 & .069 & .485 & 5.013 & 000 & .513 & 1.948 \\
\hline
\end{tabular}

a. Dependent Variable: Jiwa Wirausaha

(Sumber: Data primer diolah 2019)

Berdasarkan tabel Coefficients di atas dapat diperoleh persamaan linier berganda sebagai berikut :

$\mathrm{Y}=\mathrm{a}+\mathrm{a}_{1} \mathrm{X}_{1}+\mathrm{a}_{2} \mathrm{X}_{2}+\mathrm{e}$

$\mathrm{Y}=12.934+0.265 \mathrm{X}_{1}+0.344 \mathrm{X}_{2}$

1. Koefisien regresi pada variabel minat berwirausaha adalah 0,265 menyatakan setiap penambahan variabel minat berwirausaha sebesar $1 \%$ maka terjadi kenaikan jiwa wirausaha sebesar 26,5\%
2. Koefisien regresi pada variabel motivasi berwirausaha adalah 0,344 menyatakan setiap penambahan variabel motivasi berwirausaha sebesar $1 \%$ maka terjadi kenaikan jiwa wirausaha sebesar $34.4 \%$

Uji signifikansi parameter individual ( uji statistik $t$ ), Uji $\mathrm{t}$ dimaksudkan untuk mengetahui pengaruh secara parsial dari beberapa variabel bebas terhadap variabel terikat. Uji t dilakukan 
dengan membandingkan nilai $t_{\text {hitung }}$ dan $t$ tabel, Apabila $t_{\text {hitung }}>t_{\text {tabel }}$ maka $\mathrm{H}_{0}$ ditolak, artinya variabel bebas mempengaruhi variabel terikat secara signifikan. Berdasarkan perhitungan coefficient dengan $\mathrm{df}=106$, maka $\mathrm{t}$ tabel $=1.982$ diperoleh hasil sebagai berikut:

Tabel 5. Hasil Signifikansi Parsial

\begin{tabular}{|c|c|c|c|}
\hline Variabel & $\mathrm{t}_{\text {hitung }}$ & $\mathrm{t}_{\text {tabel }}$ & Ket \\
\hline $\begin{array}{l}\text { Minat } \\
\text { berwirausa } \\
\text { ha }\end{array}$ & 2.785 & 1.982 & $t_{\text {himung }}>t_{\text {tabel }}$ \\
\hline $\begin{array}{l}\text { Motivasi } \\
\text { Berwirausa } \\
\text { ha }\end{array}$ & 5.013 & 1.982 & $t_{\text {hitung }}>t_{\text {tabel }}$ \\
\hline
\end{tabular}

Berdasarkan hasil perhitungan diketahui bahwa minat berwirausaha berpengaruh secara parsial terhadap jiwa wirausaha ditandai dengan $\mathrm{t}_{\text {hitung }} 2.785>\mathrm{t}_{\text {tabel }}$ 1.982, motivasi berwirausah berpengauh secara parsial terhadap jiwa wirausaha dengan $\mathrm{t}$ hitung $5.013>\mathrm{t}_{\text {tabel }} 1.982$.

Selain pengujian secara parsial penelitian ini juga melakukan uji signifikansi simultan ( Uji statatistik $F$ antara minat berwirausaha, motivasi berwirausaha terhadap jiwa wirausaha. berdasarkan perhitungan diperoleh hasil sebagai berikut:
Tabel 6. Hasil Uji Signifikansi Simultan

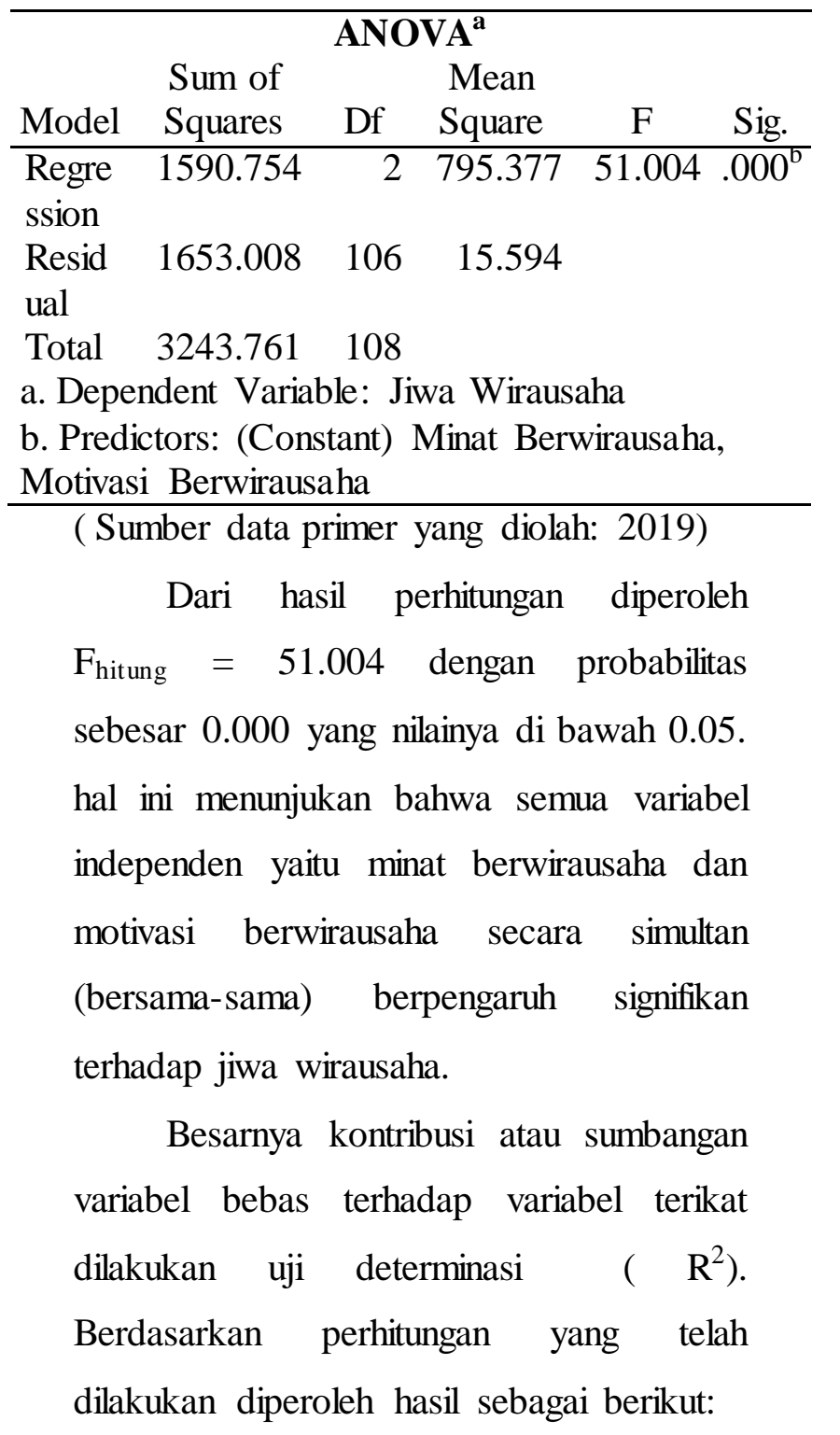

Tabel 7. Hasil Uji Koefisien Determinasi Model Summary $\mathrm{R} \quad$ Adjusted Std. Error of the $\begin{array}{llll}\text { Model } & \mathrm{R} & \text { Square } \mathrm{R} \text { Square Estimate }\end{array}$

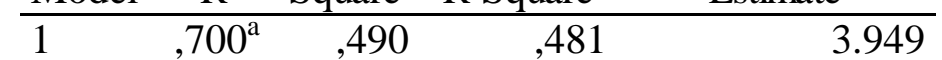
a. Predictors: (Constant) Minat Berwirausaha, Motivasi Berwirausaha ( Sumber data primer yang diolah: 2019) Koefisien determinasi (adjusted $\mathrm{R}^{2}$ ) yang diperoleh sebesar 0,481 . Hal ini berarti $48.1 \%$ Jiwa Wirausaha dapat dijelaskan oleh variabel Minat 
Berwirausaha dan Motivasi Berwirausaha, sedangkan sisanya yaitu $51.9 \%$ Jiwa Wirausaha dipengaruhi oleh variabelvariabel lainnya yang tidak diteliti dalam penelitian ini.

$$
\text { Berdasakan hasil penelitian }
$$

diketahui bahwa jiwa kewirausahaan siswa SMK Negeri 7 Kota Serang dipengaruhi minat berwirausaha dan motivasi berwirausaha siswa. Minat berwirausaha yaitu keinginan, ketertarikan, keterlibatan dalam berwirausah secara parsial signifikan mempengaruhi jiwa wirausaha demikian pula dengan motivasi berwirausaha berupa laba, kebebasan, impian personal, kemandirian secara parsial juga mempengaruhi jiwa wirausaha secara signifikan.

Jiwa wirausaha seperti pikiran, perasaan, menciptakan nilai tambah dari keterbatasan, dengan menangkap peluang bisnis dan mengelola sumber daya melalui gagasan yang inovatif ke dalam dunia nyata secara kreatif dipengaruhi secara bersama-sama oleh minat berwirausaha dan miotivasi berwirausaha. Jiwa wirausaha dipupuk dengan keinginan, ketertarikan, keterlibatan dalam berwirausaha serta laba, kebebasan, impian personal, kemandirian. Semakin tinggi minat berwirausaha dan motivasi berwirausaha akan meningkatkan pula jiwa wirausaha siswa SMK Negeri 7 Kota Serang. Pada penelitian ini minat berwirausaha dan motivasi berwirausaha dapat mempengaruhi jiwa wirausaha sebesar $48 \%$ sedangkan $52 \%$ dipengaruhi oleh hal lain.

\section{KESIMPULAN DAN SARAN}

Berdasarkan penelitian dan pembahasan yang telah dilakukan mengenai pengaruh minat dan motivasi berwirausaha terhadap jiwa wirausah siswa SMK Negeri 7 Kota Serang Tahun Ajaran 2018/2019, maka dapat ditarik kesimpulan sebagai berikut :

a. Terdapat pengaruh positif dan signifikan minat berwirausaha terhadap jiwa wirausaha pada siswa SMK Negeri 7 Kota Serang. Hal ini dibuktikan dengan hasil uji $\mathrm{t}$ dengan $\mathrm{t}_{\text {hitung }}>\mathrm{t}_{\text {tabel }}$ sebesar $(2.785>1.982)$ pada taraf signifikansi $5 \%$.

b. Terdapat pengaruh positif dan signifikan motivasi berwirausaha terhadap jiwa wirausaha pada siswa SMK Negeri 7 Kota Serang. Hal ini dibuktikan dengan hasil uji $\mathrm{t}$ dengan $\mathrm{t}_{\text {hitung }}>\mathrm{t}_{\text {tabel }}$ sebesar $(5.013>1.982)$ pada taraf signifikansi $5 \%$.

c. Terdapat pengaruh positif dan signifikan minat dan motivasi berwirausaha secara bersama-sama terhadap jiwa wirausaha pada siswa SMK Negeri 7 Kota Serang. Hal ini 
dibuktikan dengan uji regresi secara simultan antara variabel bebas dengan variabel terikat dengan $f_{\text {hitung }}>f_{\text {tabel }}$ sebesar (51.004> 3.08) pada taraf signifikansi $5 \%$.

d. koefisien determinasi (adjusted $\mathrm{R}^{2}$ ) yang diperoleh sebesar 0,481 atau sebesar $48.1 \%$, sedangkan sisanya yaitu $51.9 \%$ Jiwa Wirausaha dipengaruhi oleh variabel-variabel lainnya yang tidak diteliti dalam penelitian ini.

\section{SARAN}

Berdasarkan kesimpulan di atas dapat diajukan beberapa saran sebagai berikut:

a. Bagi Sekolah

Bagi sekolah untuk lebih menunjang kegiatan-kegiatan kewirausahaan dengan cara memfasilitasi segala hasil karya atau produk yang dihasilkan siswa.

b. Bagi Guru

Bagi guru diharapkan bisa memberikan materi-materi terutama faktor- faktor yang dapat membangkitkan minat dan motivasi siswa untuk berwirausaha lebih mendalam dan meningkatkan pelatihan secara langsung, baik dalam bentuk perencanaan, produksi, dan juga pemasaran

c. Bagi Siswa

Bagi siswa hendaknya lebih mengembangkan kompetensi yang dimiliki dengan kreatifitas sehingga bisa bersaing secara luas serta lebih mengembangkan hasil keterampilan atau produk yang dibuat.

d. Bagi Peneliti Lain

Bagi peneliti lain diharapkan dapat mengembangkan penelitian ini di masa mendatang dengan mempertimbangkan aspek lain yang berkenaan dengan jiwa wirausaha.

\section{DAFTAR PUSTAKA}

Saiman, Leonardus. (2015). Kewirausahaan Teori, Praktik, dan Kasus-kasus. Jakarta: Salemba Empat.

Suryana. (2014). Kewirausahaan. Jakarta: Salemba Empat.

\section{Internet}

4 TahunJokowi-JK, ini capaian dalam cetak wirausaha baru di Tanah Air https://www.merdeka.com/ (diakses 12 Januari 2019)

Agustus 2018: Tingkat Pengangguran Terbuka (TPT) sebesar 5,34\% https://www.bps.go.id/ (diakses 12 Januari 2019)

BPS: Jumlah Pengangguran di Banten Tertinggi di Indonesia https://www.radarbanten.co.id/ (diakses 12 Januari 2019) 
Vol 3 No. 1, Februari 2020

E-ISSN 2622-7037 |P-ISSN 2623-0763
Fu'adi, Isky Fadhli,Budiarso Eko\&Murdani (2009) Hubungan Minat Berwirausaha Dengan Prestasi Praktik Kerja Industri Siswa Kelas XI Teknik Otomotif SMK Negeri Adiwerna Kabupaten Tegal Tahun Ajaran 2008/2009. JPTM. Vol 9 No 2 Hal 93

Nurbudiyani, Iin. (2015). Manajemen Pengembangan Kewirausahaan (Enterpreneurship) Siswa SMKN2 Palangkaraya. Pedagogik Jurnal Pendidikan. Vol 10 No 1 Hal 12

Sulastri, Susi. (2017). Pengaruh Jiwa Kewirausahaan Terhadap Keberhasilan Usaha Susu Kedelai
Hanya 3,1PersenPendudukProduktif di RI yang Wirausaha https://www.cnnindonesia.com/, ( diakses 12 Januari 2019)

KeadaanKetenagakerjaanBantenAgustus $\begin{array}{lll}2018 & \text { https://banten.bps.go.id/ } \\ \text { (diakses } & 12 \text { Januari 2019) }\end{array}$ di Kecamatan Braja Selebah Lampung Timur. Dinamika. Vol 3No 2 Hal : 39.

Uswaturrasul, Yahya. \& Sisilia, Kristina. (2011). Analisis Minat dan Motivasi Berwirausaha Mahasiswa. e-Proceeding of management. $\quad 2: 358$ 
PROGRESS

Jurnal Pendid ikan, Akuntansi dan Keuangan Universitas Banten Jaya
Vol 3 No. 1, Februari 2020

E-ISSN 2622-7037 |P-ISSN 2623-0763 